\title{
IIIness Perception in Different Clinical Categories of Patients with Familial Hypercholesterolaemia
}

\author{
Salmi Razali1,3, Zaliha Ismail2,4, \\ Najib Abdullah ${ }^{3}$, Hapizah M Nawawi ${ }^{4}$
}

\author{
1 Department of Psychiatry, \\ 2Department of Public Health Medicine, \\ ${ }^{3}$ Department of Psychiatry and Mental Health, Hospital Sg Buloh, \\ ${ }^{4}$ Institute of Pathology, Laboratory and Forensic Medicine (I-PPerForM) \\ Faculty of Medicine, Universiti Teknologi MARA, \\ 47000 Sungai Buloh, Selangor, Malaysia
}

drsalmi@gmail.com, drzie65@gmail.com, muhdnajibabdullah@gmail.com, hapizah.nawawi@gmail.com

\begin{abstract}
Understanding illness perception is crucial to ensure healthy lifestyles. However, it has been poorly explained to inform effective lifestyle modification of patients with Familial Hypercholesterolaemia (FH) Therefore, we described the illness perception of different clinical categories of $\mathrm{FH}$ patients (using the Dutch Lipid Clinic Criteria (DLCC) and investigate its association with sociodemographic and illnessrelated factors. Illness perception of $\mathrm{FH}$ patients varies according to the level of education and the presence of CVD. Patients with 'definite' FH have the highest emotional disturbances. These findings may help clinicians to improve the interventions suitable for $\mathrm{FH}$ patients.

Keywords: Familial hypercholesterolaemia; illness perception; DLCC; cardiovascular disease

eISSN 2514-7528 @ 2019. The Authors. Published for AMER ABRA cE-Bs by e-International Publishing House, Ltd., UK. This is an open-access article under the CC BY-NC-ND license (http://creativecommons.org/licenses/by-ncnd/4.0/). Peer-review under responsibility of AMER (Association of Malaysian Environment-Behaviour Researchers), ABRA (Association of Behavioural Researchers on Asians) and cE-Bs (Centre for EnvironmentBehaviour Studies), Faculty of Architecture, Planning \& Surveying, Universiti Teknologi MARA, Malaysia. DOI: https://doi.org/10.21834/jabs.v4i13.332
\end{abstract}




\subsection{Introduction}

National Health and Morbidity Survey (2015), indicated that $47.7 \%$ of the adults in Malaysia may have hypercholesterolaemia and the number is growing. Together with hypertension, diabetes, obesity and smoking, hypercholesterolemia increases the risk for Cardiovascular Diseases (CVDs); the leading causes of morbidity and mortality in this country. CVDs is preventable through a combination of lipid-lowering medications and healthy lifestyle (Hagger, Hardcastle, Kwok \& Nawawi et al., 2018a).

Previously, one method of reducing unhealthy behaviour and encouraging healthy lifestyles was by changing the type of coping with the illness (Hsiao, Chang, \& Chen, 2012). Later, since it has been shown that changing patients' illness perception leads to a better adherence to cholesterol-lowering medication (Senior, Marteau, \& Weinman, 2004) and recovery following CVDs (Petrie, Cameron, Ellis, Buick, \& Weinman, 2002), it would be better to modify patients' illness perceptions at the earlier stage rather than educating them with coping strategies at the later stage (Hsiao et al., 2012).

\subsection{Literature Review}

Hypercholesterolemia is caused by primary and secondary factors. While various secondary factors have been identified, including hypothyroidism, nephrotic syndrome, cholelithiasis, obesity and many others. One of the most important primary hypercholesterolaemia is Familial Hypercholesterolaemia (FH), the most common autosomal dominant genetic disorder in humans, linked to low-density lipoprotein receptor (LDLR) and apolipoprotein B100 genes mutation (Al-Khateeb et al., 2016; Azian et al., 2006). It is characterised by marked elevation of low-density lipoprotein cholesterol (LDL-C), leading to increased risk of developing premature coronary artery disease (CAD).

Several clinical diagnostic criteria for $\mathrm{FH}$ are available, including the Dutch Lipid Clinic Criteria (DLCC)(WHO Report, 2013) and Simon Broome (SB) Registry (Scientific Steering Committee 1991, National Collaborating Centre for Primary Care and RCGP 2008). These clinical tools can predict the presence of mutations in $\mathrm{FH}$. The DLCC is widely recommended in Europe and also being widely used worldwide (WHO Report, 2013). It is similar to the SB Register criteria but each criterion is given a weightage (Box 1).

How do individuals comprehend their illness? To answer this question, Leventhal et al. (1984) had come up with the self-regulation model. The symptoms and emotions felt by an individual after a diagnosis give effect on the perception of illness and one's subsequent coping behaviour (Leventhal et al., 1984). The study further suggests that situational stimuli such as symptoms of diseases create cognitive and emotional representations of the illness are vitals in determining the behaviours related to the illness. These are managed in three phases, specifically the portrayal of the health hazard, the actions undertaken in coping with it and finally the assessment of the effectiveness of these behaviours (Leventhal et al., 1984).To healthcare practitioners, the measurement of patient's illness perception is crucial to individually specify and determine their clinical management (Frich, Ose, Malterud, \& 
Fugelli, 2006). According to Morgan, Villiers-Tuthill, Barker, and McGee (2014), awareness and comprehension of patient's illness perception on the part of the doctor would help in ensuring that there is no irrelevant expectation from treatment.

To date, very little findings come from Malaysia and its Asian neighbours. This serves as a great obstacle for clinicians as without local evidence, they could not possibly provide comprehensive management of $\mathrm{FH}$ for the local population. Just of late have researchers from the Asia-Pacific Region and the Southern Hemisphere, including Malaysia, shown some interest in understanding FH and its correlates (Pang et al., 2017; Watts et al., 2016). This research work termed as 'Ten Countries Study' centres upon FH patients, delving further into areas such as illness perception, health literacy, diagnostic, epidemiological and service aspects, as well as physician practices of FH (Hagger, 2018b; Pang et al., 2017; Razak et al., 2016; Watts et al., 2016).

Realising the sparse in data locally on illness perceptions among different clinical categories of $\mathrm{FH}$ patients, and its contributing factors, this study aimed to i) identify the pattern of illness perception of different clinical categories of $\mathrm{FH}$ patients and ii) determine correlated factors for illness perceptions including the role of background sociodemography and $\mathrm{FH}$ illness-related factors. We hypothesised that different clinical categories of $\mathrm{FH}$ patients have various patterns of illness perception and those with high education and multiple complications would have acceptable illness perception.

\subsection{Methodology}

This was a cross-sectional study, using convenient sampling, collecting data at the Specialist Lipid and Coronary Risk Prevention Clinics in a Teaching Hospital in Malaysia. The patients diagnosed with FH according to DLCC and aged 18 years or more were enrolled. The DLCC is a validated set of criteria based on the patient's personal coronary heart disease history, patient's untreated LDL-c levels and physical signs such as tendon xanthomata or arcus cornealis before the age of 45 and family history of premature CVD in their first-degree relatives. Scores were given for each criterion and the participants were categorised as having 'definite', 'probable', or 'possible' FH. The participant with the total score of more than eight is considered as having 'definite' $\mathrm{FH}$; a total score between six and eight indicates 'probable' FH, and the score between three and five is 'possible' FH (Box 1). Written informed consent was obtained from all subjects before being enrolled in this study. Institutional Research Ethical Committee approval [600-RMI (5/1/6)].

We invented a self-reported pro forma questionnaires to gather information on sociodemographic background and illness-related factors. Information on sociodemography includes data regarding gender, age, marital status, level of education and their total household income per month. Illness characteristics include the presence of CVDs, type of CVDs (including coronary heart disease, angina, stroke, atherosclerosis and peripheral vascular disease), treatment for $\mathrm{FH}$, and risk factors for coronary artery disease (including smoking status, high blood pressure, depression and high stress). 
Box 1. Dutch Lipid Clinic Criteria

\begin{tabular}{|c|c|}
\hline $\begin{array}{l}\text { Criteria } \\
\text { Family History: } \\
\text { A First degree relative with known premature }(<55 \text { years men; }< \\
60 \text { years women) coronary disease and vascular disease OR LDL- } \\
\text { c > 95th percentile } \\
\text { B First degree relative with tendon xanthomata and/or } \\
\text { arcuscornealis OR childhood (<18years) with LDL-c }>95^{\text {th }} \\
\text { percentile }\end{array}$ & $\begin{array}{l}\text { Points } \\
1 \\
2\end{array}$ \\
\hline $\begin{array}{l}\text { Clinical history: } \\
\text { A Patient with premature } \operatorname{CAD} \text { ( men }<55 \text {, women }<60 \text { years) } \\
\text { B Patient with premature cerebral or } \operatorname{PVD~(~} \text { men }<55 \text {, women }<60 \\
\text { years) }\end{array}$ & $\begin{array}{l}2 \\
1\end{array}$ \\
\hline $\begin{array}{l}\text { Physical Examination: } \\
\text { A Tendon xanthomas } \\
\text { B Premature arcus }\end{array}$ & $\begin{array}{l}6 \\
4 \\
\end{array}$ \\
\hline $\begin{array}{l}\text { Lab analysis } \\
\text { A LDL -c }>8.5 \mathrm{mmol} / \mathrm{L} \\
\mathrm{B} L D L-c 6.5-8.4 \mathrm{mmol} / \mathrm{L} \\
\mathrm{C} L D L-c 5.0-6.4 \mathrm{mmol} / \mathrm{L} \\
\mathrm{D} L D L-c 4.0-4.9 \mathrm{mmo} / \mathrm{L}\end{array}$ & $\begin{array}{l}8 \\
5 \\
3 \\
1\end{array}$ \\
\hline $\begin{array}{l}\text { Functional } \\
\text { DNA mutations }\end{array}$ & 8 \\
\hline Definite FH :> 8 points, Probable FH: 6-8 points, Possible & \\
\hline
\end{tabular}

A revised illness perception questionnaire (IPQ-R) was used to measure participants' illness perception (Moss-Morris et al., 2002). There are three parts of the questionnaire. The first part asking participants about 'identity' and enquiring them about some potential physical symptoms of $\mathrm{FH}$. The participants also have to respond Yes or No, whether they have ever encountered any of the symptoms as a consequence of their illness.

The second part of IPQ-R dealings with perceptions of the likely period of the illness such as lasting for a brief period or passes rapidly; enduring rather than short-lived; this is called the 'timeline' component of illness perception. The timeline 'cyclical' component, defines fluctuations of symptoms of illness either changes a countless deal from day to day; wax and wane in cycles or very erratic. In addition, the 'consequences' component measures one's thoughts about the illness severity and the possibility of effects on physical, social and psychological functioning. This part of the questionnaire also measures the 'personal control' component which indicates the 'treatment control' or the degree to which the patient thinks that their ailment is amenable to cure or control. Moreover, the 'illness coherence' component asks their degree of understanding of the illness such as whether they have a poor or strong understanding of the illness.

Finally, the 'emotional changes' components describe their emotional states after having the illness including feeling distress, scared, irritated, worry, anxious or dismayed with the 
illness. Participants were required to answer questions on a 5-point Likert-type scale (from disagree strongly to agree strongly).

Analyses used Statistical Package for the Social Sciences (SPSS) version 24. The differences between score means of different domains were compared using Independent ttest. In addition, Mann Whitney test and Kruskal Wallis test were used to determine the possible associations between respondent characteristics and domains of illness perceptions. This project was approved by the Institutional Research Ethics committee (600$\operatorname{RMI}(5 / 1 / 6)$.

\subsection{Results}

Hundred participants who have 'definite' (32\%), 'probable' (58\%) and 'possible' (10\%) FH using DLCC were recruited in the study. They were majority female (63\%) and mainly from a lower socioeconomic and $55 \%$ attained up to the secondary level of education with a total household income less than RM3000 a month. The participants were predominantly in the late forties (age mean+SD: 49.8 \pm 11.4 years) and ever married individuals (92\%) (Table 1).

Of the total participants who have $\mathrm{FH}, 41 \%$ have CVDs; mainly coronary heart disease $(n=35 ; 85.4 \%)$, angina $(n=8 ; 19.5 \%)$, atherosclerosis $(n=4 ; 9.8 \%)$, stroke $(n=4 ; 9.8 \%)$ and one participant has peripheral arterial disease. About two-thirds (69\%) of the participants received lipid-lowering agents. More than a third (40\%) of the participants had hypertension, $13 \%$ were smokers, and $8 \%$ reported feeling stressed up and complained of feeling depressed. When the classification of $\mathrm{FH}$ is taking into account, percentages of illness related factors varies according to different clinical categories (Table 1).

\subsection{IIIness perceptions}

More than $90 \%$ of the participants did not complain of most of the physical symptoms due to $\mathrm{FH}$, except for fatigue (16\%) and sleeping difficulties (12\%). It was found that the rating of a number of symptoms that the patient sees as part of the illness or 'identity' element was significantly higher among those who were receiving treatment compared to those were not $(z=-2.662, p=0.008)$ (There was no association between those who experience physical symptoms and DLCC FH criteria (Table 2 and Table 3 ).

Table 1: The sociodemographic and illness factors in relation to $\mathrm{FH}$ classification

\begin{tabular}{lrrrr}
\hline \multicolumn{4}{c}{ FH Classification $\mathrm{n}(\%)$} \\
\hline & Definite & Probable & Possible & P-value \\
\hline Variable & & & & \\
Age [mean(SD)] years & $49.2(11.6)$ & $47.5(15.8)$ & $50.5(10.5)$ & 0.704 \\
$\begin{array}{c}\text { Gender, } \mathrm{n}(\%) \\
\quad \text { Males }\end{array}$ & $17(27.0)$ & $10.0(15.9)$ & $36(57.1)$ & 0.027 \\
$\quad$ Females & $15(40.5)$ & 0 & $22(59.5)$ & \\
Marital status & & & & \\
$\quad$ Unmarried & $3(37.5)$ & $2(25.0)$ & $3(37.5)$ & 0.545
\end{tabular}




\begin{tabular}{lrrrr} 
Ever married & $29(31.5)$ & $8(8.7)$ & $55(59.8)$ & \\
$\begin{array}{l}\text { Education } \\
\text { Pre-university and }\end{array}$ & $12(37.5)$ & $4(8.3)$ & $32(66.7)$ & \\
university & & & & \\
Secondary school & $16(50.0)$ & $6(13.6)$ & $22(50.0)$ & \\
$\quad$ Primary and below & $4(12.5)$ & $0(0)$ & $4(50.0)$ & \\
Illness-related factors & & & & \\
Cardiovascular disease & & & & \\
Yes & $13(31.7)$ & $5(12.2)$ & $23(56.1)$ & 0.827 \\
No & $19(32.2)$ & $5(8.5)$ & $35(59.3)$ & \\
Types of CVD & & & & \\
Coronary heart disease & $12(34.2)$ & $4(11.4)$ & $19(54.2)$ & 0.850 \\
Angina & $3(30.0)$ & $2(20.0)$ & $5(50.0)$ & 0.536 \\
Atherosclerosis & $1(20.0)$ & $1(20.0)$ & $3(60.0)$ & 0.682 \\
Stroke & $1(25.0)$ & & $3(75.0)$ & 0.709 \\
Peripheral vascular & 0 & $1(100)$ & 0 & 0.011 \\
$\quad$ disease & & & & \\
Receiving treatment for FH & & & & \\
Yes & $25(36.2)$ & $5(7.2)$ & $39(56.5)$ & 0.221 \\
Presence of risk factor & & & & \\
Smoker & $6(46.2)$ & $2(15.4)$ & $5(38.5)$ & 0.308 \\
High blood pressure & $15(37.5)$ & $4(10.0)$ & $21(52.5)$ & 0.613 \\
Depression & $4(50.0)$ & $1(12.5)$ & $3(37.5)$ & 0.457 \\
High stress & $2(25.0)$ & 0 & $6(75.0)$ & 0.488 \\
\hline
\end{tabular}

\subsection{Sociodemography and illness perceptions}

We found that $\mathrm{FH}$ patients who had successfully achieved at least secondary education had the highest score for 'treatment control' (median score=18.0; IQR=2.75) than others in different levels of education (Table 2). Also, participants who reached only primary level of education had the highest score for 'cyclical' element (median score=13; IQR=3.0) followed by those who achieved secondary education and then tertiary (or pre-university and university level of education). Other analyses were not significant.

\subsection{IIIness factors and illness perceptions}

IIIness perceptions between different groups of FH patients were different in terms of 'identity', 'cyclical' and 'emotional changes'(Refer Table 3). Participants who had CVDs reported higher scores in 'consequences' elements than those who did not have CVDs $(t=0.385, p<0.001)$. This group of $\mathrm{FH}$ patients also reported significantly reporting that their illness was 'cyclical' in nature higher than those without CVDs $(t=-3.047 ; p=0.003)$. They also significantly had a higher score in 'emotional changes' than those without CVDs ( $\mathrm{t}=-2.409 ; \mathrm{p}=0.018)$. Also, $\mathrm{FH}$ patients with multiple risk factors also have significantly higher 'cyclical' element than those with only a single risk factor $(z=-1.847 ; p=0.038)$. There was no difference in terms of 'personal control', 'treatment control' and 'illness coherence' between different groups of illness factors 
(Table 3).

\subsection{Discussion}

Prevention of CVDs should begin as early as possible to minimise complications and reduce the substantial price hikes of future healthcare associated with the disease. However, this study shows that $\mathrm{FH}$ patients still have poor insight on the importance of preventive measures. This is reflected when only FH patients who had several risk factors and those who had developed multiple types of CVDs were more concerned with their illness than those with $\mathrm{FH}$ only. Most of them described the progression of their ailment as wax and wane or 'cyclical' in nature instead of understood that $\mathrm{FH}$ is a genetic condition that is long-lasting. In a qualitative study, a similar finding was found that most $\mathrm{FH}$ patients were not focused on the heredity aspects of the illness (Weiner \& Durrrington, 2018). Furthermore, regardless of having the complications, these groups of FH patients had lack of ability to regulate and had a poor understanding of their illness, they also lack belief in the effectiveness of their treatment as illustrated in the IPQ-R components; 'personal control', 'treatment control' and 'illness coherence'. These findings are similar to those found in patients with coronary heart disease (Foxwell, Morley, \& Frizelle, 2013). Hence, these findings call for more health education for $\mathrm{FH}$ patients to improve their knowledge and understanding of the course of illness and its treatment.

We found the knowledge and insight on the complications of their disease occurred only when they had already developed CVDs. It is easy to speculate that this happens because of the lack of distinctive signs and symptoms of $\mathrm{FH}$ at the initial phase of the illness. Most often, apart from the elevated level of cholesterol and the presence of lipid stigmata, only subtle clinical presentations seen and detected by the clinicians, causing early detection is challenging (Alicezah, Rahman, \& Koshy, 2014). It may be possible that if insight and understanding of the illness among $\mathrm{FH}$ patients can be imparted at the early period of the disease, the overall clinical consequence can be further improved.

This study indicated that many FH patients did not describe the 'consequences' or the possibility of $\mathrm{FH}$ effecting their physical, social and psychological functioning. They only realised that $\mathrm{FH}$ causes a variety of consequences when the complication set in. The findings were similar in other medical circumstances which have trifling signs and symptoms at the initial stage of illness such as hypertension and diabetes mellitus (Petriček et al., 2009; Ross, Walker, \& MacLeod, 2004). This pattern of illness perception has been explained by the selfregulation model; that the presence of symptoms becomes the threat or stimulus, triggering further subsequent behaviour such as coping, planning and appraisal of how to take the medication appropriately according to prescription and engaging with lifestyle modification (Leventhal et al., 1984). Preferably, regulating FH should begin even before the appearance of symptoms and complication of illness. The complexity of behaviours in response to illness have encouraged a few scholars to propose self-regulation model, social self-efficacy, health literacy, individual attitudes, subjective norms and perceived behavioural control (Hagger et 
al., 2016; Hagger et al., 2018).

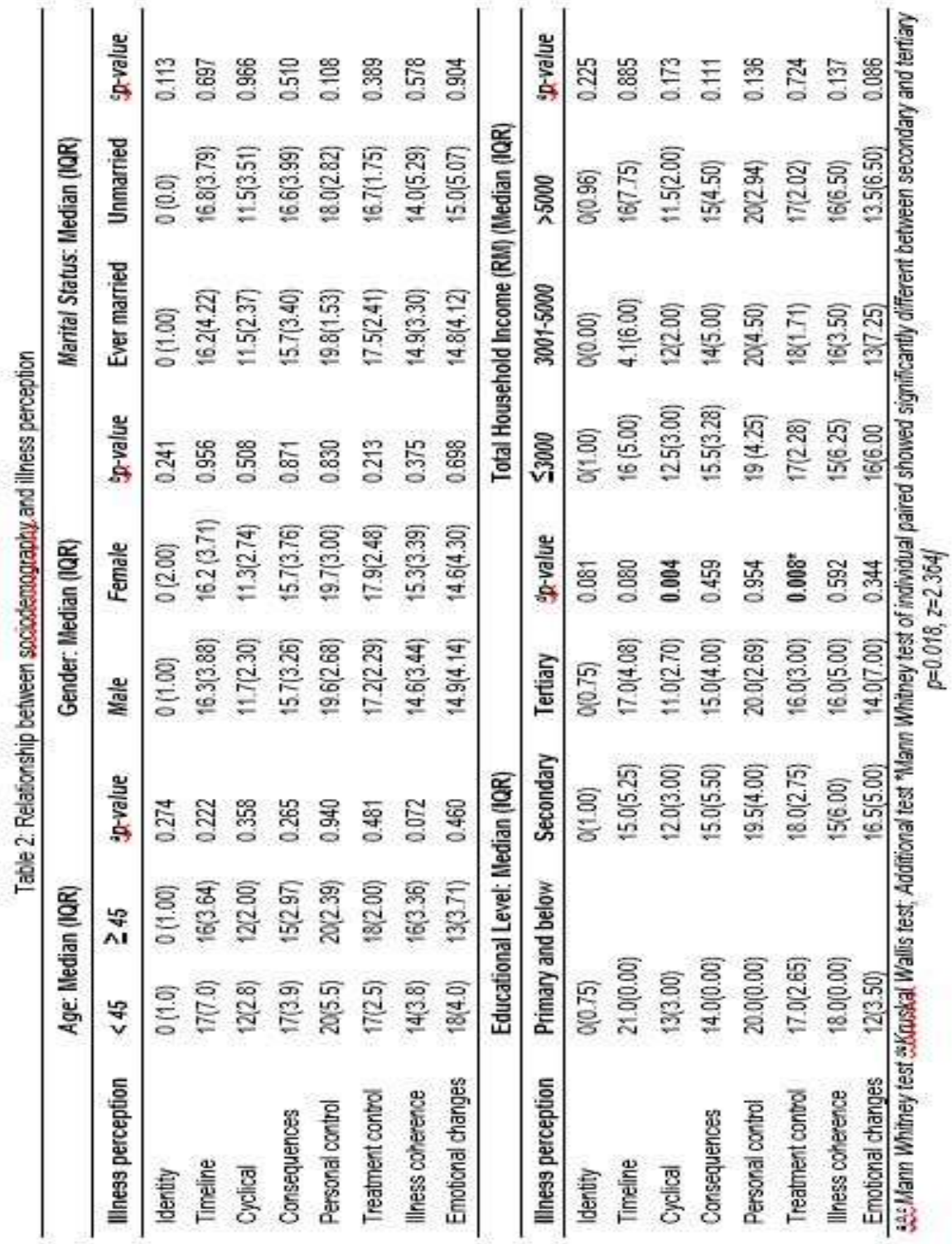




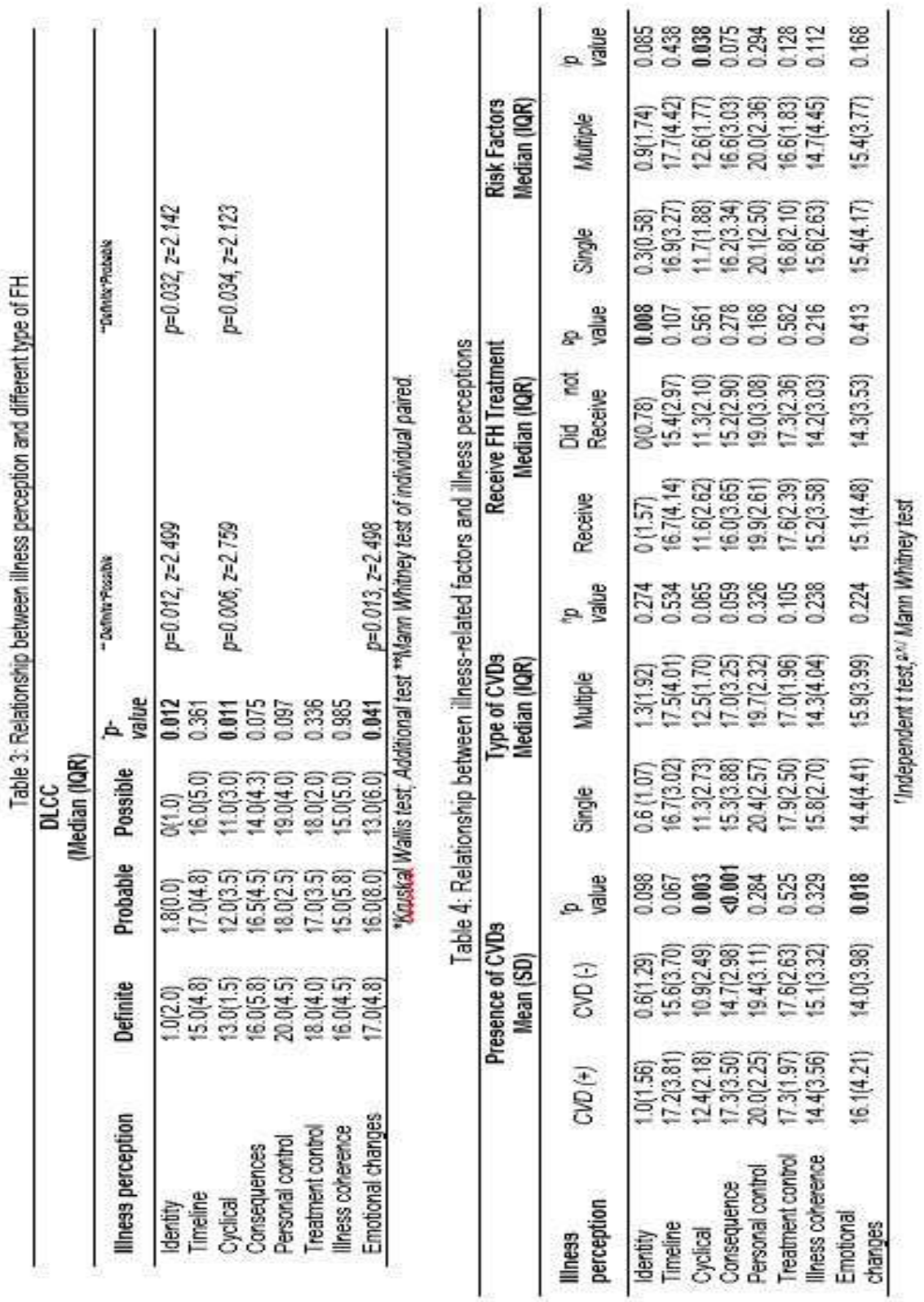


FH patients with CVDs in this study reported significant emotional instabilities compared to those without CVDs. Furthermore, a high percentage of $\mathrm{FH}$ patients believed that having stress as part of the contributing factors for their disease. This is not a new finding. Patients with CVDs have been described by many scholars before to have psychological disorders such as chronic distress, depression, anxiety and dementia (Cohen, Edmondson, \& Kronish, 2015). Interestingly, we have added to this understanding that those who had been diagnosed with 'definite' FH suffered the most emotional changes. Presence of emotional instabilities may disturb routine activities, disease progression, quality of life, functions and mortality of patient with CVDs (Foxwell et al., 2013). Thus, to successfully manage FH patients, those with psychological conflicts should be carefully monitored and managed by using holistic interventions comprise effective psychotropic medications in combination with caring and collective care from various disciplines in medicine.

\subsection{Conclusion}

Management of $\mathrm{FH}$ patients is not merely prescribing the lipid-lowering medications, giving advice for weight management and suggesting a healthy balanced diet to prevent the complications; understanding the perception of the patients is vital so that they adhere to the treatment plan. In order to do so, the foremost crucial step is to understand their illness perception that determines the subsequent lifestyle behaviours. Informed by the findings from our study, we understood that FH patients have gained insight on their illness only when the symptoms and complications of the disease have set in and three elements (level of education, the presence of CVD and level of emotional disturbances) play vital roles in how they perceived their illness. Hence, clinicians should provide early health education (in particular for those with low education) to enhance their understanding of the illness as early as possible. Furthermore, concerted effort with mental health professionals is crucial to address their emotional distress. We would like to highlight that the study is restricted with small sample size and we are aware that many other cultural beliefs that could influence their illness perceptions.

\section{Acknowledgement}

This study was funded by UiTM MITRA Grant [grant code: 600-IRMI/MYRA 5/3/MITRA (003/2017)-2)] and Pfizer International 'Asia Pacific Translational Research for Improving the care of FH 10 Countries Study - Malaysian substudy' Grant [100-RMI/INT 16-/6/2(3/2015)] awarded to the corresponding author. We would like to thank Professor Gerald Watts, the Chief Investigator of the FH Ten Countries Study, for facilitating the study; and Professor Martin Hagger from Curtin University, for providing the modified IPQ-R questionnaire. 


\section{References}

Al-Khateeb, A., Hamzan, N. S., Razali, R., Froemming, G. A., Rahman, T., Peng, H. B., \& Nawawi, H. (2016). Genetic Study of Low-Density Lipoprotein Receptor Gene and Apolipoprotein B-100 Gene among Malaysian Patients with Familial Hypercholesterolaemia. International Archives of Medicine, 9.

Azian, M., Hapizah, M., Khalid, B., Khalid, Y., Rosli, A., \& Jamal, R. (2006). Use of the denaturing gradient gel electrophoresis (DGGE) method for mutational screening of patients with familial hypercholesterolaemia $(\mathrm{FH})$ and Familial defective apolipoprotein B100 (FDB). The Malaysian Journal of Pathology, 28(1), 7-15.

Cohen, B. E., Edmondson, D., \& Kronish, I. M. (2015). State of the art review: depression, stress, anxiety, and cardiovascular disease. American Journal of Hypertension, 28(11), 1295-1302.

Foxwell, R., Morley, C., \& Frizelle, D. (2013). Illness perceptions, mood and quality of life: a systematic review of coronary heart disease patients. Journal of Psychosomatic Research, 75(3), 211-222.

Frich, J. C., Ose, L., Malterud, K., \& Fugelli, P. (2006). Perceived vulnerability to heart disease in patients with familial hypercholesterolaemia: a qualitative interview study. The Annals of Family Medicine, 4(3), 198-204.

Hagger, M.S., Hardcastle, S.J., Hu M, Kwok, S, Lin J, Nawawi, H.M., Pang, J, Santos, R.D., Soran, H., Su TC, Tomlinson, B, Watts, G.F. (2018a) Effects of Medication, Treatment, and Behavioral Beliefs on Intentions to Take Medication in Patients with Familial Hypercholesterolemia. Atherosclerosis for the FH special issue, Atherosclerosis; 277: 493-501.

Hagger, M.S., Hardcastle, S.J., Hu M, Kwok, S, Lin J, Nawawi, H.M., Pang, J, Santos, R.D., Soran, H., Su TC, Tomlinson, B, Watts, G.F. (2018b) Health literacy in familial hypercholesterolemia: A cross-national study. European Journal of Preventive Cardiology: DOI: 10.1177/2047487318766954

Hagger, M. S., Hardcastle, S. J., Hingley, C., Strickland, E., Pang, J., \& Watts, G. F. (2016). Predicting selfmanagement behaviours in familial hypercholesterolaemia using an integrated theoretical model: The impact of beliefs about illnesses and beliefs about behaviours. International Journal of Behavioral Medicine, 23(3), 282-294.

Hsiao, C.-Y., Chang, C., \& Chen, C.-D. (2012). An investigation of illness perception and adherence among hypertensive patients. The Kaohsiung Journal of Medical Sciences, 28(8), 442-447.

Institute for Public Health (IPH). (2015). National Health and Morbidity Survey 2015 (NHMS 2015). Vol. II: NonCommunicable Diseases, Risk Factors \& Other Health Problems; 2015.

Leventhal, H., Nerenz, D. R., \& Purse, J. (1984). Illness representations and coping with health threats: Baum, A., Taylor, S.E. and Singer, J.E. Eds., Handbook of Psychology and Health, Volume IV: Social Psychological Aspects of Health, Erlbaum, Hillsdale, NJ, 219-252.

Alicezah M.K., Rahman, M.T. \& Koshy, M. (2014). Homozygous familial hypercholesterolaemia. The Malaysian Journal of Pathology, 36(2), 131.

Morgan, K., Villiers-Tuthill, A., Barker, M., \& McGee, H. (2014). The contribution of illness perception to psychological distress in heart failure patients. BMC Psychology, 2(1), 50.

Moss-Morris, R., Weinman, J., Petrie, K., Horne, R., Cameron, L., \& Buick, D. (2002). The revised illness perception questionnaire (IPQ-R). Psychology and Health, 17(1), 1-16. 
National Collaborating Centre for Primary Care and Royal College of General Practitioners. Identification and management of Familial hypercholesterolaemia (FH). London, UK; Royal College of General Practitioners, 2008. www.nice.org.uk/nicemedia/live/12048/41700/41700.pdf. Accessed June 12, 2013

Pang, J., Hu, M., Lin, J., Miida, T., Nawawi, H. M., Park, J. E., . . Gonzalez-Santos, L. E. (2017). An enquiry based on a standardised questionnaire into knowledge, awareness and preferences concerning the care of familial hypercholesterolaemia among primary care physicians in the Asia-Pacific region: the 'Ten Countries Study'. BMJ Open, 7(10), e017817.

Petriček, G., Vrcić-Keglević, M., Vuletić, G., Cerovečki, V., Ožvačić, Z., \& Murgić, L. (2009). Illness perception and cardiovascular risk factors in patients with type 2 diabetes: cross-sectional questionnaire study. Croatian Medical Journal, 50(6), 583-593.

Petrie, K. J., Cameron, L. D., Ellis, C. J., Buick, D., \& Weinman, J. (2002). Changing illness perceptions after myocardial infarction: an early intervention randomized controlled trial. Psychosomatic Medicine, 64(4), 580-586.

Razak, S. A., Rahmat, R., Kasim, N. M., Rahman, T. A., Muid, S., Nasir, N. M., . . Nawawi, H. (2016). Diagnostic performance of various familial hypercholesterolaemia criteria compared to the Dutch lipid clinic criteria in an Asian population. Atherosclerosis, 252, e27-e28.

Ross, S., Walker, A., \& MacLeod, M. J. (2004). Patient compliance in hypertension: the role of illness perceptions and treatment beliefs. Journal of Human Hypertension, 18(9), 607.

Scientific Steering Committee on behalf of the Simon Broome Register Group. Risk of fatal coronary heart disease in Familial Hypercholesterolaemia. BMJ 1991;303:893-896

Senior, V., Marteau, T., \& Weinman, J. (2004). Genetic Risk Assessment for FHTSG. Self-reported adherence to cholesterol-lowering medication in patients with familial hypercholesterolaemia: The role of illness perceptions. Cardiovasc Drugs Ther, 18, 475-481.

Watts, G. F., Ding, P. Y., George, P., Hagger, M. S., Hu, M., Lin, J., . . Nawawi, H. M. (2016). Translational research for improving the care of familial hypercholesterolaemia: the 'ten countries study' and beyond. Journal of Atherosclerosis and Thrombosis, 23(8), 891-900.

Weiner K. \& Durrington P.N.(2008). Patients' Understandings and Experiences of Familial Hypercholesterolemia, Public Health Genomics, 11 (5), 273-282. doi: 10.1159/000121398

Witteman, C., Bolks, L., \& Hutschemaekers, G. (2011). Development of the illness perception questionnaire mental health. Journal of Mental Health, 20(2), 115-125.

World Health Organisation. Report of a Second WHO Consultation. Geneva, Switzerland: WHO; 1999. whqlibdoc.who.int/hq/ 1999/WHO_HGN_FH_CONS_99.2pdf. Accessed June 12, 2013 